\title{
Endosymbiotic Yeast Maternally Transmitted in a Marine Sponge
}

\author{
MANUEL MALDONADO ${ }^{1, *}$, NURIA CORTADELLAS ${ }^{2}, \mathrm{M}^{\mathrm{a}}$ ISABEL TRILLAS ${ }^{3}$, \\ AND KLAUS RÜTZLER ${ }^{4}$ \\ ${ }^{1}$ Department of Aquatic Ecology, Centro de Estudios Avanzados de Blanes (CSIC), Acceso Cala \\ St. Francesc 14, E-17300 Blanes, Girona, Spain; ${ }^{2}$ Serveis Cientifico-Tecnics, Universitat de Barcelona, \\ Lluís Solé Sabarís 1-3, E-08028 Barcelona, Spain; ${ }^{3}$ Departament of Biologia Vegetal, Facultat de \\ Biología, Universitat. de Barcelona, Av. Diagonal 645, E-08028 Barcelona, Spain; and ${ }^{4}$ Department of \\ Invertebrate Zoology/CCRE/MRC 163, Smithsonian Institution, 1000 Constitution Ave. NW, PO Box \\ 37012, Washington, DC 20013-7012
}

\begin{abstract}
The detection of an endosymbiotic yeast in demosponges of the genus Chondrilla described here records the first such association within the phylum Porifera. The symbiont, interpreted as a yolk body in previous ultrastructural studies, is a chitinous-walled fission yeast. Chitin was detected by an immunocytochemical technique that labels its $\beta-1,4-N$-acetyl-D-glucosamine residues. Abundant symbiotic yeast cells $\left(4.4 \pm 2.3\right.$ cells per $\left.10 \mu \mathrm{m}^{2}\right)$ transmitted from the soma through the oocytes to the fertilized eggs are directly propagated by vertical transmission in the female. Vertically transmitted yeast were detected in three Chondrilla species with disjunct biogeographical distributions: the Mediterranean, the Caribbean, and the Australian Pacific. Apparently these yeasts are not present in other demosponge genera. Therefore, the fungal endosymbiosis most likely evolved before or during the diversification of the genus Chondrilla.
\end{abstract}

\section{Introduction}

Sponges have long been recognized as prolific sources of compounds of biomedical interest, but only recently was it realized that some of these molecules are not produced by the sponges themselves. The idea that microsymbionts may provide some of the "sponge bioactive molecules" sparked when bacteria and several hyphal fungi isolated in laboratory cultures from sponges and

Received 14 March 2005; accepted 15 August 2005.

* To whom correspondence should be addressed. E-mail: maldonado@ ceab.csic.es other marine animals yielded not only new natural products, but also compounds identical or related to those formerly attributed to their hosts (e.g., Unson et al., 1994; Imhoff and Störh, 2003; Proksch et al., 2003; Bringmann et al., 2003). Although many transmission electron microscopy (TEM) studies have demonstrated impressive bacterial populations within sponge tissues (e.g., Vacelet, 1970, 1975; Vacelet and Donadey, 1977; Wilkinson, 1978a-c; Simpson, 1984; Rützler, 1990; Maldonado and Young, 1998), the presence of endosymbiotic fungi has yet to be confirmed visually. Furthermore, some hyphal fungi isolated from sponges and other invertebrates have recently been identified as members of non-marine genera, such as Penicillium and Aspergillium (e.g., Bringmann et al., 2003), arousing suspicion that the alleged symbiotic fungi grew from non-marine dormant propagules only in the laboratory (Proksch et al., 2003). This uncertainty is reflected by a change in the terminology, with early claims of "sponge-symbiotic fungi" being recently reconsidered as "sponge-associated fungi." While chemists have continued investigations on the interesting novel compounds of the isolated fungi, documentation of a sponge fungal endosymbiosis is still lacking.

A fine-structural study of the reproductive biology of Caribbean populations of the demosponge Chondrilla nucula led us to investigate various cell inclusions. By applying immunocytochemical methods we are able to demonstrate for the first time the occurrence of an endosymbiotic yeast in a marine sponge. 


\section{Materials and Methods}

\section{Sampling}

In summer 2002, we sampled by scuba diving a reproductive population of the gonochoristic demosponge Chondrilla aff. nucula Schmidt (Chondrillidae, Chondrosida), established on a shallow reef at Lee Stocking Island (The Bahamas). Further ecological information on the sponge population can be found elsewhere (Maldonado et al., 2005). It has recently been suggested that Caribbean and Mediterranean populations of Chondrilla nucula are unlikely to be conspecific (Klautau et al., 1999), but no further action has been taken to taxonomically split the complex. Therefore, we will use the established name Chondrilla nucula to refer to the Caribbean stock, with the caveat that it represents a distinct species yet to be formally named. Histological samples consisted of small tissue pieces from reproductive males and females, as well as mucous strands of mature eggs obtained from the exhalant canals of ripe females by finger pressure. After collection, samples were immediately transported to the laboratory in seawater-filled vials.

\section{Transmission electron microscopy}

The collected material was fixed and embedded following standard protocols for studying animal rather than fungal cells, because we were unaware of the occurrence of an endosymbiotic fungus. Fixation for conventional transmission electron microscopy (TEM) took place about $1 \mathrm{~h}$ after sample collection. Primary fixation was in $2.5 \%$ glutaraldehyde in $0.2 M$ Millonig's phosphate buffer (MPB) and 0.14 $M$ sodium chloride for $1 \mathrm{~h}$ (see Maldonado et al., 2003). Samples were then rinsed with MPB for $40 \mathrm{~min}$, postfixed in $2 \%$ osmium tetroxide in MPB, dehydrated in a graded acetone series, and embedded in Spurr's resin. Ultrathin sections obtained with an Ultracut Reichert-Jung ultramicrotome were mounted on gold grids and stained with $2 \%$ uranyl acetate for $30 \mathrm{~min}$, then with lead citrate for $10 \mathrm{~min}$ (Reynolds, 1963). Observations were conducted with a JEOL 1010 transmission electron microscope operating at $80 \mathrm{kV}$ and provided with a Gatan module for acquisition of digital images.

\section{Immunocytochemical labeling}

To investigate the fungal nature of some sponge endosymbionts, we used the lectin wheat germ agglutinin (WGA)-bovine serum albumin (BSA)-gold complex (Horisberger and Rosset, 1977). The complex labels the $\beta$-1,4- $N$-acetyl-D-glucosamine residues of chitin walls (Peter and Latka, 1986; Benhamou and Lafontaine, 1995; Trillas et al., 2000). We obtained colloidal gold particles of $12-17 \mathrm{~nm}$ by reducing $0.01 \%$ (w/v) tetrachloroauric acid with $1 \%$ (w/v) aqueous-Tris-sodium citrate (Frens, 1973).
Then, we coupled $1 \mathrm{mg}$ of WGA with $4.0 \mathrm{mg}$ of BSA in 5 $\mathrm{mM} \mathrm{NaCl}$, adjusting the reaction to $\mathrm{pH} 7.4$ with $\mathrm{K}_{2} \mathrm{CO}_{3}(0.2$ $\mathrm{N}$ ), subsequently cross-linking with $0.25 \%$ glutaraldehyde. After $2 \mathrm{~h}$, we added $5 \mathrm{mM} \mathrm{NaCl}$ and filtered the solution through a $0.45-\mu \mathrm{m}$ Millipore filter. Lectin-BSA conjugate $(50-75 \mu \mathrm{l})$ was used to stabilize $500 \mu \mathrm{l}$ of colloidal gold at $\mathrm{pH}$ 7.4. After centrifugation $\left(50,000 \times \mathrm{g}\right.$ at $\left.4{ }^{\circ} \mathrm{C}\right)$ for $1 \mathrm{~h}$, the resulting complex was stabilized with $10 \mu \mathrm{l}$ of $0.02 \%(\mathrm{w} / \mathrm{v})$ polyethylene glycol, then used to incubate the ultrathin sections at room temperature for $2 \mathrm{~h}$. We assayed the effectiveness of the labeling complex by running preliminary incubations at various experimental concentrations (i.e., 1/2,1/5,1/10,1/50). Ultrathin sections of a laboratory culture of the Fusarium oxysporum fungus (Trillas et al., 2000) served as positive control for the labeling reaction, and sponge cells lacking chitin served as negative controls.

\section{Results}

\section{Microsymbionts in sponge eggs}

At first glance, TEM examination of unfertilized eggs revealed just two types of microsymbionts: heterotrophic bacteria and cyanobacteria (Fig. 1a-d). Both were inside vacuoles, without direct contact with the egg cytoplasm. Heterotrophic bacteria were mostly rods with a relatively electron-clear wall and ranging in size from $0.5 \times 0.1 \mu \mathrm{m}$ to $1.4 \times 0.6 \mu \mathrm{m}$ (Fig. 1b, c). Nevertheless, at least one possible coccoid type appears to occur, characterized by small size $(0.3 \times 0.5 \mu \mathrm{m}$ average $)$ and an electron-dense wall that distinguishes it from transversely sectioned rods (Fig. 1b, c). The cyanobacteria, which commonly measure from $1 \times 0.4 \mu \mathrm{m}$ to $1.9 \times 0.9 \mu \mathrm{m}$, appear to belong to a single type (Fig. 1d), traditionally described as Aphanocapsa feldmani; this species was recently redescribed as Synechococcus spongiarium on the basis of $16 \mathrm{~s}$ rDNA analyses of Mediterranean and Australian populations of Chondrilla nucula (Usher et al., 2004a). A few cyanobacteria slightly longer than $2 \mu \mathrm{m}$ were also observed, and were found to be stages engaged in cell division (not shown).

Apart from heterotrophic bacteria and cyanobacteria, major components of the egg were glycogen granules and lipid droplets, as well as subspherical membrane-bounded inclusions 1.2-2 $\mu \mathrm{m}$ in diameter (Figs. 1a-c; 2a). The latter, which occur at densities of $4.4 \pm 2.3$ cells per $10 \mu \mathrm{m}^{2}$, are virtually identical to those described as "complex yolk bodies" in the eggs of both Mediterranean populations of Chondrilla nucula (Gaino, 1980) and the Australian C. australiensis (Usher et al., 2001, 2004b). However, the chitin-targeted gold marker selectively labeled the electronclear envelope of these presumed yolk inclusions, revealing that they are fungus cells rather than yolk (Fig. 2b). Furthermore, we found complex yolk bodies (Fig. 2c), which are similar in size to fungal bodies but different in structure, containing a distinctive electron-dense multilamellar enve- 
a
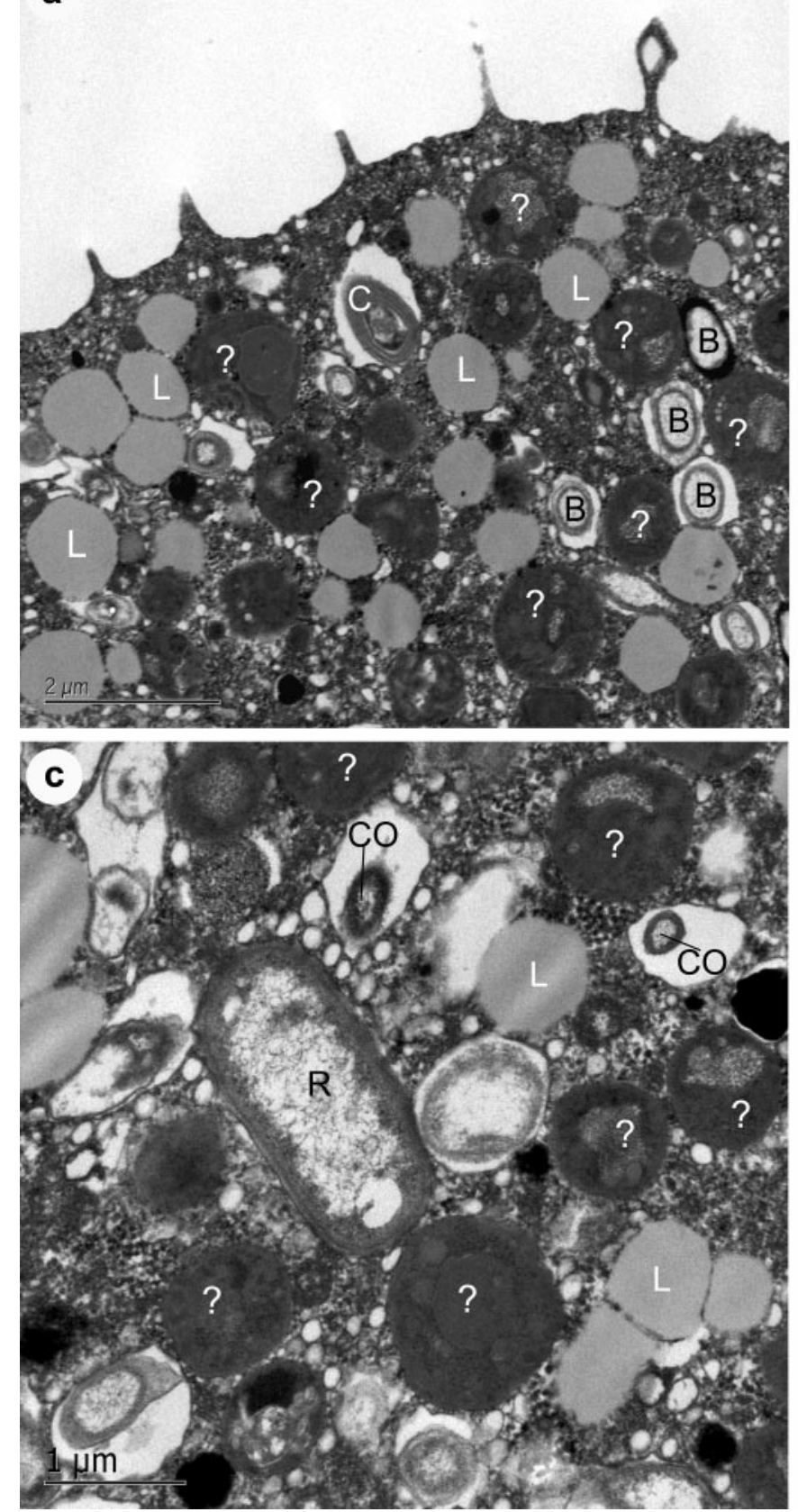
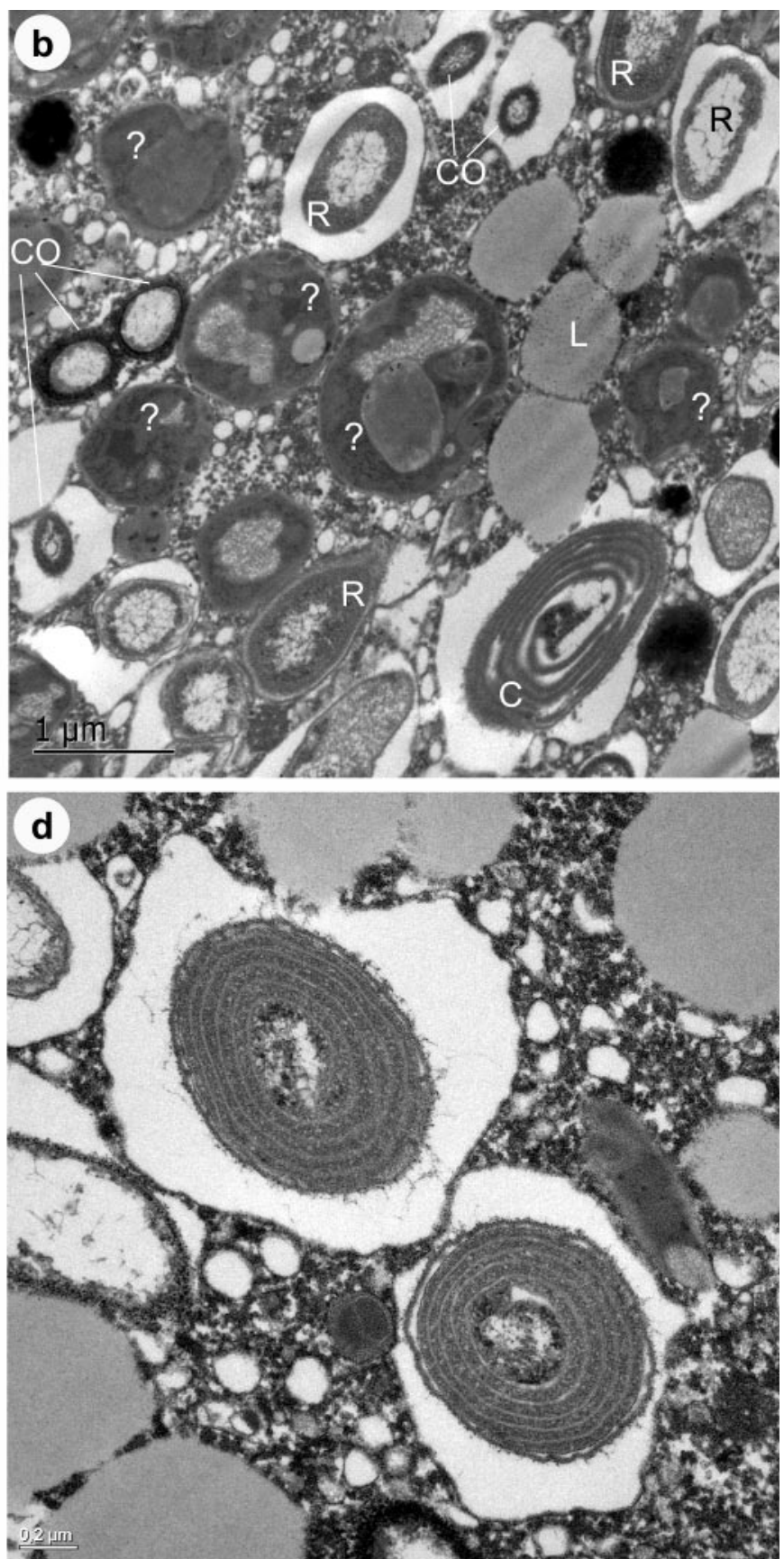

Figure 1. Mature oocytes of Chondrilla nucula. (a) Abundance of heterotrophic bacteria (B), cyanobacteria (C), and enigmatic subspherical membrane-bounded inclusions (?), along with lipid granules (L), within the peripheral zone of a mature egg. (b, c) Bacterial diversity illustrated by large rods $(\mathrm{R})$ and small putative coccids (CO) with electron-dense wall, along with cyanobacteria. (d) Detail of two cyanobacteria.

lope and striated vitelline platelets (Fig. 2c, d). The idea that the enigmatic bodies are yeasts was further corroborated when we observed some of them in stages of asexual reproduction by fission (Fig. 3a, b). Fission scars and newly formed wall (division septum) were intensely marked by the colloidal gold (Fig. 3a, b), indicating that chitin concentrates in these areas, as typically described for yeasts
(Walker, 1998). The fact that these organisms were consistently single-celled, without hyphal or pseudomycelial stages, corroborated their yeast-like nature.

The subcellular structure of nondividing stages also corresponded to that of yeasts, consisting of an anucleolate nucleus, a large vacuole, an electron-dense peroxisome, abundant ribosomes, and an electron-clear multilamellar 

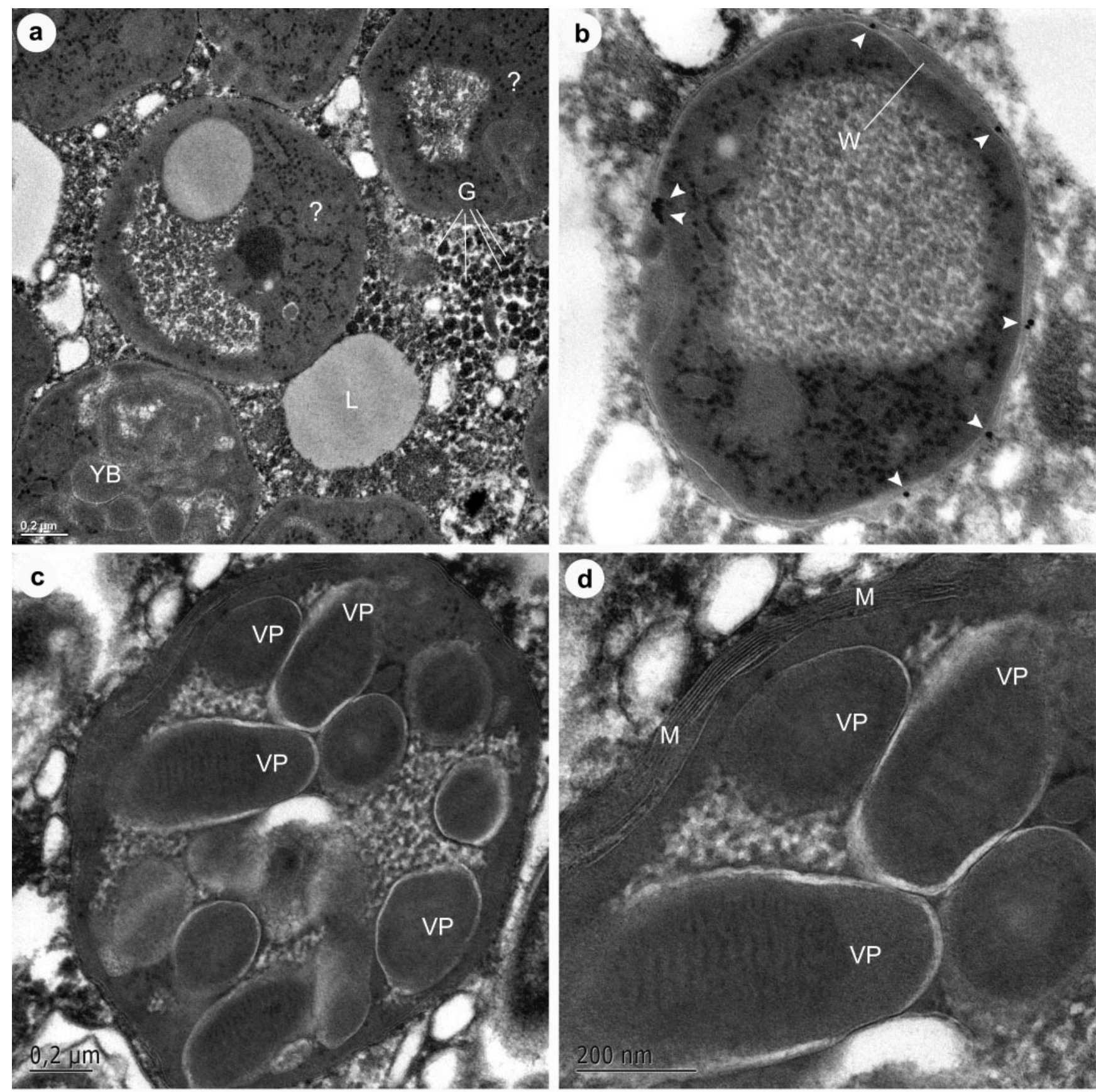

Figure 2. Details of the "complex" inclusions of oocytes. (a) Enigmatic subspherical membrane-bounded inclusion (?) showing that it has an internal organization quite different from that seen in a complex yolk body (YB). Note that the oocyte cytoplasm is rich in glycogen granules (G) and lipid granules (L). (b) Colloidal gold labeling the "envelope" of a subspherical inclusion (arrowheads), indicating that it is a cryptic yeast with chitin in its wall (W). (c) Complex yolk body containing vitelline platelets (VP) of striated structure. (d) Detail of Fig. $2 \mathrm{c}$ showing the multilayered electron-dense membrane $(\mathrm{M})$ of the yolk body, and some vitelline platelets (VP).

wall (Fig. 4a-d). Unusually small and scarce mitochondria, endoplasmic reticulum, and Golgi apparatus were occasionally visible within the electron-dense cytoplasm (Fig. 4b, c). The vacuole wall was often labeled with colloidal gold (Fig. 5a), indicating a probable role in storage of chitin precursors to produce new wall during fission. In fact, once nuclear division is achieved, the vacuole becomes disorganized and its content is used to assemble a membrane system that participates in the formation of the new septum between the daughter yeasts (Fig. 5b-e). Chitin-specific labeling is more 

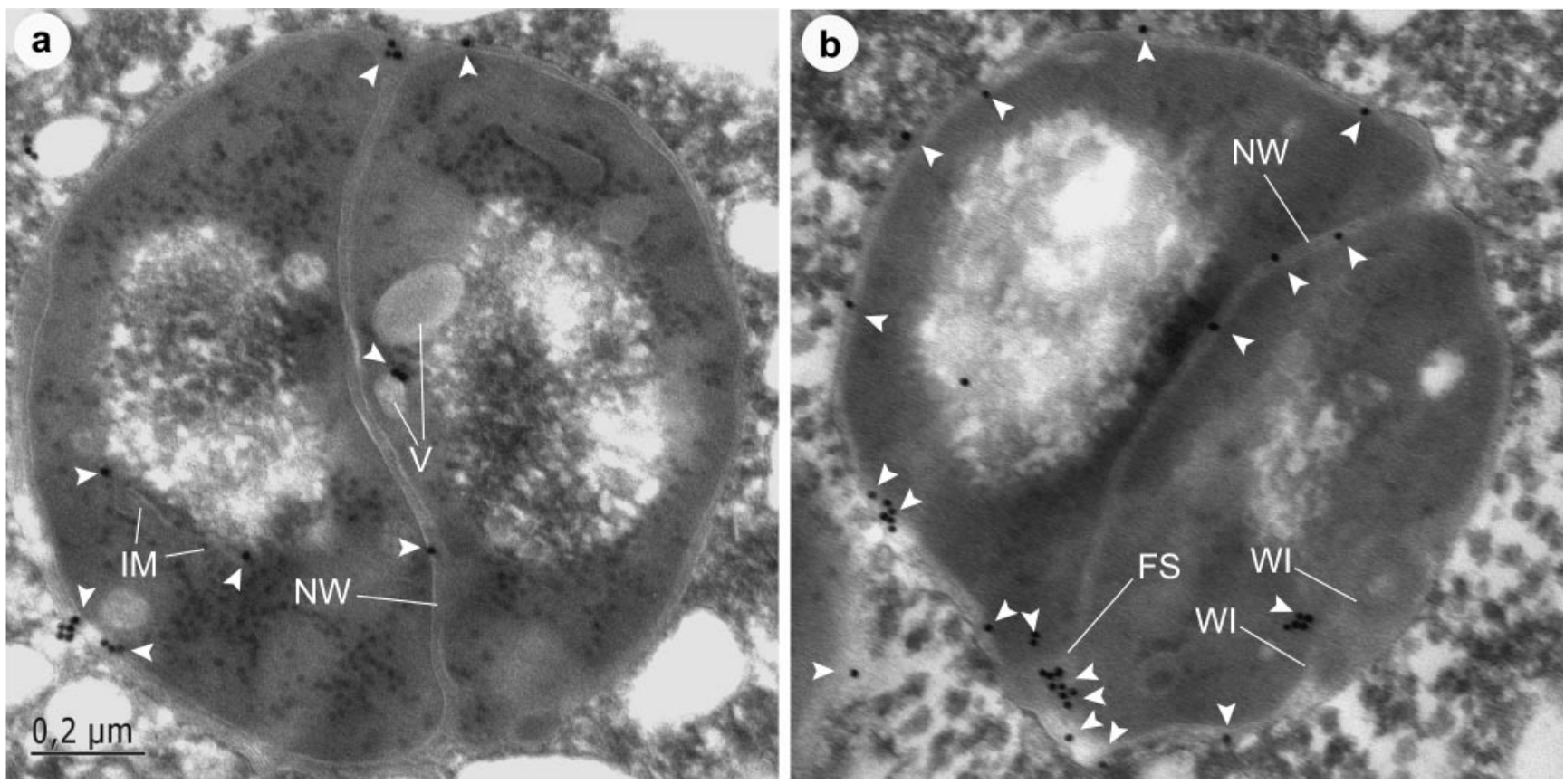

Figure 3. ( $a, b)$ Newly divided yeasts after fission, showing accumulation of gold particles in the electronclear chitin wall (arrowheads), particularly in the newly produced wall (NW), wall invaginations (WI), and wall thickenings (fission scars $=$ FS) resulting from previous fission events. Some internal membrane systems (IM) and the vacuole wall (V) are also labeled (see also Fig. 5).

intense in newly formed cell wall than in "old" wall (Fig. $5 \mathrm{~d}$ ), indicating that chitin in newly formed wall is either more abundant or more accessible to the marker.

The fact that the nuclear membrane and the mitochondria are not clearly distinguishable in most of our micrographs of intact yeasts within the oocytes is probably a consequence of having used a fixation method more appropriate for animal than yeast cells; the method for yeast cells involves digestion of the cell wall prior to fixation, to facilitate permeation of fixatives (see Bauer et al., 2001). Interestingly, both the nuclear and the mitochondrial membranes were clearly visible in degenerating yeasts that became external to the host, because the oocytes in which they were contained burst accidentally prior to fixation (Fig. 6a-e). Oocyte bursting released yeasts into the mucous matrix that embeds oocyte groups to form the so-called "egg strands," in which eggs are collectively expelled from the sponges. Inspection of these "externalized" endosymbionts by TEM revealed that the wall of most heterotrophic bacteria and yeasts had degenerated to various degrees (Fig. 6c, d), while most cyanobacteria showed no appreciable degradation (not shown). Most internal organelles of the externalized yeasts also showed some level of degradation, but mitochondrial, peroxisomal, nuclear, and cell membranes became better preserved than those in intact yeasts occurring within the oocytes (Fig. 6b-e). For unknown reasons, the Golgi membranes, which were clearly visible in intact yeasts within the oocytes, became unidentifiable in these degenerating yeasts.

\section{Microsymbionts in adult tissue}

TEM examination of adult sponge tissue revealed abundant intercellular symbiotic bacteria and cyanobacteria located in the peripheral mesohyl (Fig. 7a-c), as known from earlier histological descriptions of Mediterranean specimens of Chondrilla nucula. We also observed abundant yeasts (Figs. 7a-d; 8a-d), which occurred at intracellular and intercellular locations, not only in female sponges but also in males. The presence of yeasts in tissue of male sponges disproves the traditional view that these bodies could be yolk inclusions. Interestingly, yeasts were never found in sperm cells (sperm not shown).

In addition to bacteria, cyanobacteria, and yeasts, we found the symbiotic dinoflagellate Symbiodinium microadriaticum (Fig. 9). We hypothesize that dinoflagellates were acquired accidentally from some of the many zooxanthellate corals that share habitat with the sponge in the reef. Such an idea is supported by both the rare occurrence of dinoflagellates in the sponge tissue and their intercellular location, which contrasts with the typical intracellular location reported for the true endosymbiotic dinoflagellates described in other sponges (e.g., Rützler, 1990; Rosell, 1993). 

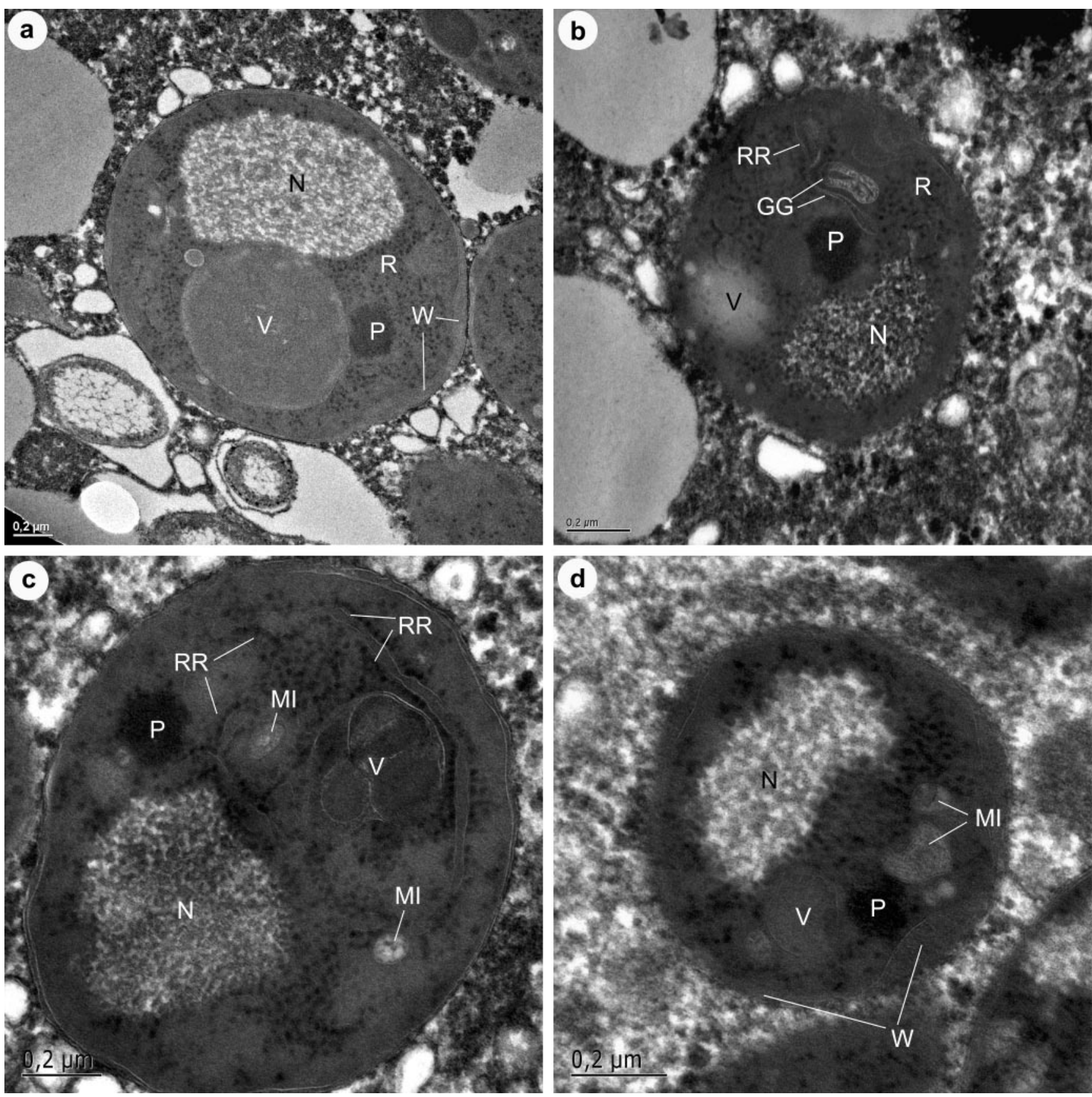

Figure 4. (a-d) Micrographs of four yeast cells showing a distinctive wall (W), an anucleolated nucleus (N), a vacuole $(\mathrm{V})$, a peroxisome $(\mathrm{P})$, abundant ribosomes $(\mathrm{R})$, rough endoplasmic reticulum (RR), Golgi apparatus (GG), and putative mitochondria (MI).

Because yeasts, like heterotrophic bacteria and cyanobacteria, concentrate in the peripheral body region of Chondrilla whereas eggs develop in the basal zone, amoeboid sponge cells move about the peripheral mesohyl during ovogenesis, selectively engulfing-but not digestingyeasts, other microsymbionts, and yolk precursors (Fig. $7 \mathrm{a}-\mathrm{d})$. These contents are later incorporated into the growing oocytes. In the beginning, the amoeboid cells (usually referred to as nurse cells) have a nucleolate nucleus and contain either isolated yeasts or yeast groups (Fig. 7b-d). It is noteworthy that yeast groups are enclosed within a membrane, but isolated yeasts occur in direct contact with the cell cytoplasm (Figs. 7b-d; 8a-b). In a later stage, the nurse cells cease their engulfing activity, become spherical, and enucleate themselves before transferring their content to the oocyte (Fig. 8c, d). Some of the smaller anucleate nurse 

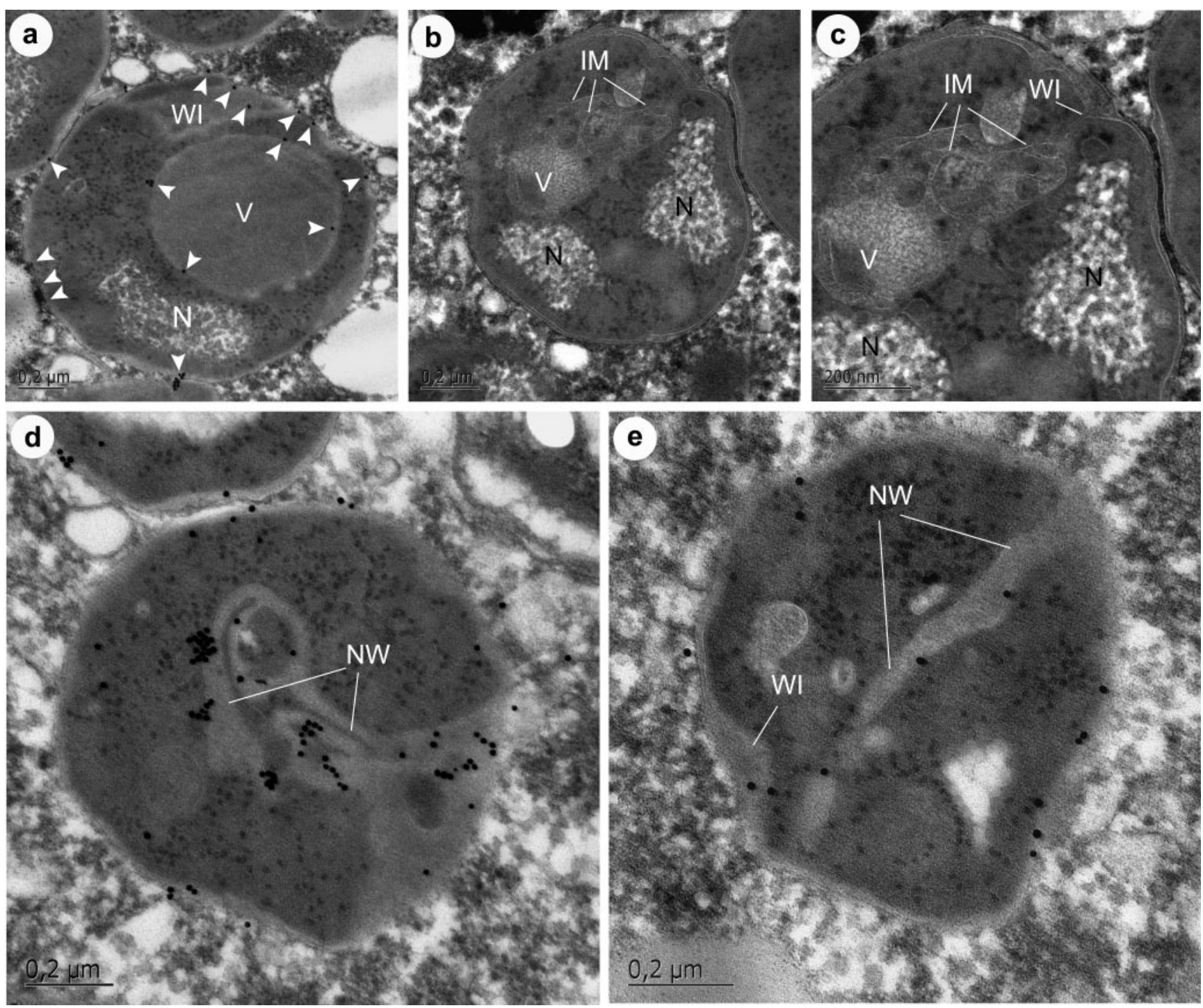

Figure 5. Stages of the fission process. (a) Nondividing yeast with intense labeling in the cell wall (arrowheads) and wall invaginations (WI). Note the large vacuole (V), the envelope of which also shows labeling by gold particles revealing the presence of chitin (arrowheads). (b) Yeast after nuclear (N) division but prior to cytokinesis, showing a disorganized vacuole $(\mathrm{V})$ producing a system of internal membranes (IM). (c) Detail of Fig. 5b showing how the internal membranes (IM) are connected to an invagination of the external chitin wall (WI). (d) Yeast forming a new division septum (NW) by connecting the material resulting from the disorganization of the vacuoles and the invagination of the cell wall. Note that gold labeling is more intense in the developing wall than in the "old" cell wall, indicating that chitin is either more abundant or more accessible to the marker in the former. (e) Yeast showing a dividing septum of new wall (NW). Note labeling of both new and old wall by gold particles.

cells appear to be engulfed by larger amoeboid nurse cells (Fig. 8a), which explains the occurrence of membranebounded inclusions containing either yeast groups or a heterogeneous mix of microsymbionts and lipids (Figs. 7d; $8 \mathrm{a}, \mathrm{b})$. Prior to spawning, the mature oocytes and their associated population of nurse cells migrate from the mesohyl to the exhalant canals of the sponges. In these canals, oocytes awaiting release are accompanied by abundant large ( 2 to $10 \mu \mathrm{m}$ ) anucleate cells charged with microsymbionts, vitelline platelets, and lipids (Fig. 8c). This observation suggests that oocytes are incorporating yolk and symbionts from nurse cells until the very last moment before spawning. Indeed, we found anucleate nurse cells engulfing bacteria from the water of exhalant canals (Fig. 7d). Nevertheless, we failed to visualize nurse cells transferring their content to the oocytes at any stage. Therefore, it remains unclear whether symbiont transference takes place by engulfment of entire nurse cells by the oocytes or by direct 

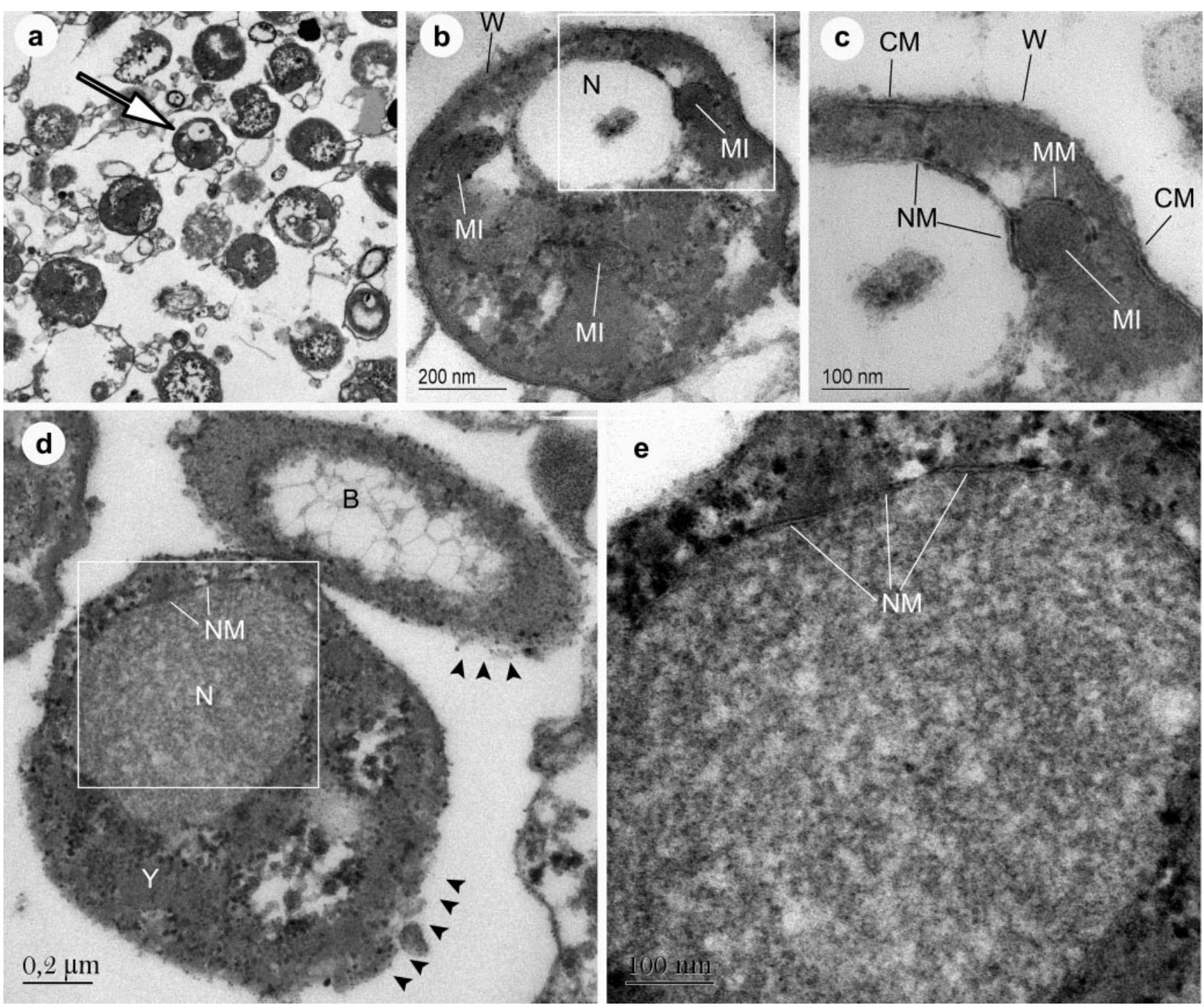

Figure 6. Yeasts exposed to seawater. (a) Yeasts, bacteria, and lipid granules set free by accidental breakage of an oocyte within the mucous strands. The arrow points to the yeast cell magnified in Figs 6b-c. (b) Magnification of yeast cell in Fig 6a, showing a partially degraded wall (W), an empty nucleus (N), and several mitochondria (MI). (c) Enlarged area of Fig. 6b, showing remains of a degraded cell wall (W) and the two-layer structure of the cell membrane (CM), the nuclear membrane (NM), and the mitochondrial membrane (MM). (d) Details of a yeast $(\mathrm{Y})$ and bacterium (B) occurring free within the mucous strands, showing their wall and some peripheral internal regions partially degraded (arrowheads). The yeast shows a large nucleus $(\mathrm{N})$ with a patent nuclear membrane (NM). (e) Enlarged area of Fig. 6d, showing the typical two-layer structure of the nuclear membrane (NM).

release of the content of the nurse cells within the oocyte after fusion of their plasmalemmae.

It is noteworthy that many nurse cells burst (apoptosis?) in the excurrent aquiferous canals, releasing their cytoplasmic compounds and symbionts into the seawater. As a result, the eggs become embedded within a greenish-brown mucous matrix and are finally expelled by the sponge in the form of mucous strands that sink to the bottom. TEM observations indicate that yeasts and heterotrophic bacteria appear to degenerate rapidly within the mucous medium of the strands.

\section{Discussion}

Our TEM examination of eggs and adult tissue of Caribbean individuals of Chondrilla nucula confirmed the presence of abundant endosymbiotic heterotrophic bacteria, cyanobacteria, and fission yeasts. The occurrence of yeasts 

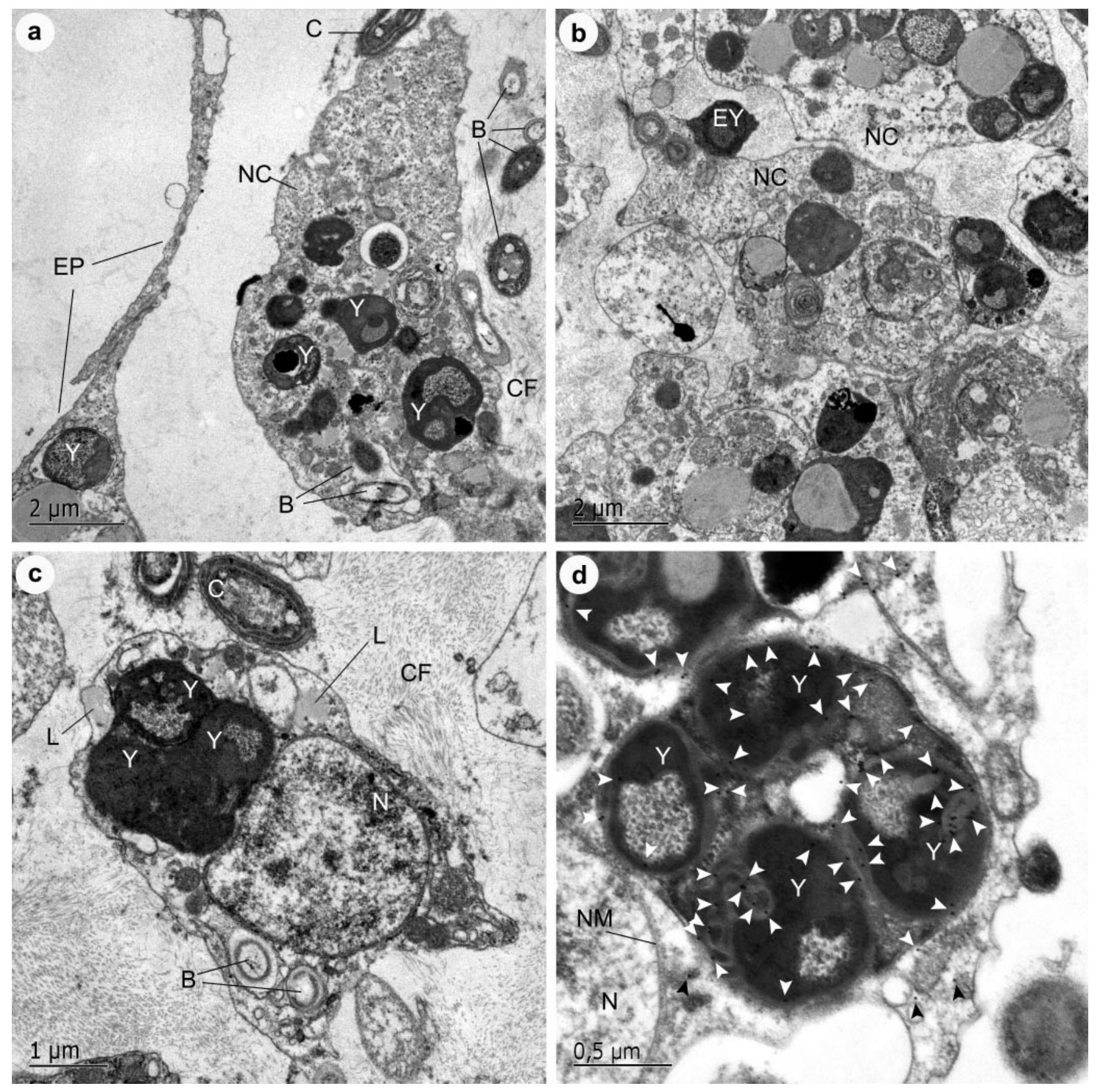

Figure 7. Yeasts in tissue of female sponges. (a) General view of a peripheral sponge region showing endopinacocytes (EP), a mesohyl sponge cell (NC), an intercellular matrix of collagen fibrils (CF), and abundant intracellular and intercellular microsymbionts, such as cyanobacteria $(\mathrm{C})$, bacteria $(\mathrm{B})$, and yeasts $(\mathrm{Y})$. Note occurrence of yeasts in both the pinacocytes and mesohyl cells. (b) Occurrence of an intercellular yeast cell (EY) between two amoeboid mesohyl cells (nurse cells $=\mathrm{NC}$ ) charged with lipids and diverse symbionts. (c) Detail of a nucleate $(\mathrm{N})$ nurse cell inside a collagen $(\mathrm{CF})$-rich mesohyl, carrying several lipid granules $(\mathrm{L})$, undigested bacteria (B), and a membrane-bounded complex inclusion containing several yeasts (Y). (d) Detail of a complex, membrane-bounded inclusion located by the side of the nuclear membrane $(\mathrm{NM})$ of a nucleate $(\mathrm{N})$ nurse cell. The inclusion contains four yeasts (Y), the cell wall and internal vacuoles of which are intensely marked by colloidal gold particles (white arrowheads). Note that yeast labeling is highly specific, despite the fact that some occasional gold particles remain in the nurse-cell cytoplasm after rinsing off the labeling solution (black arrowheads). 

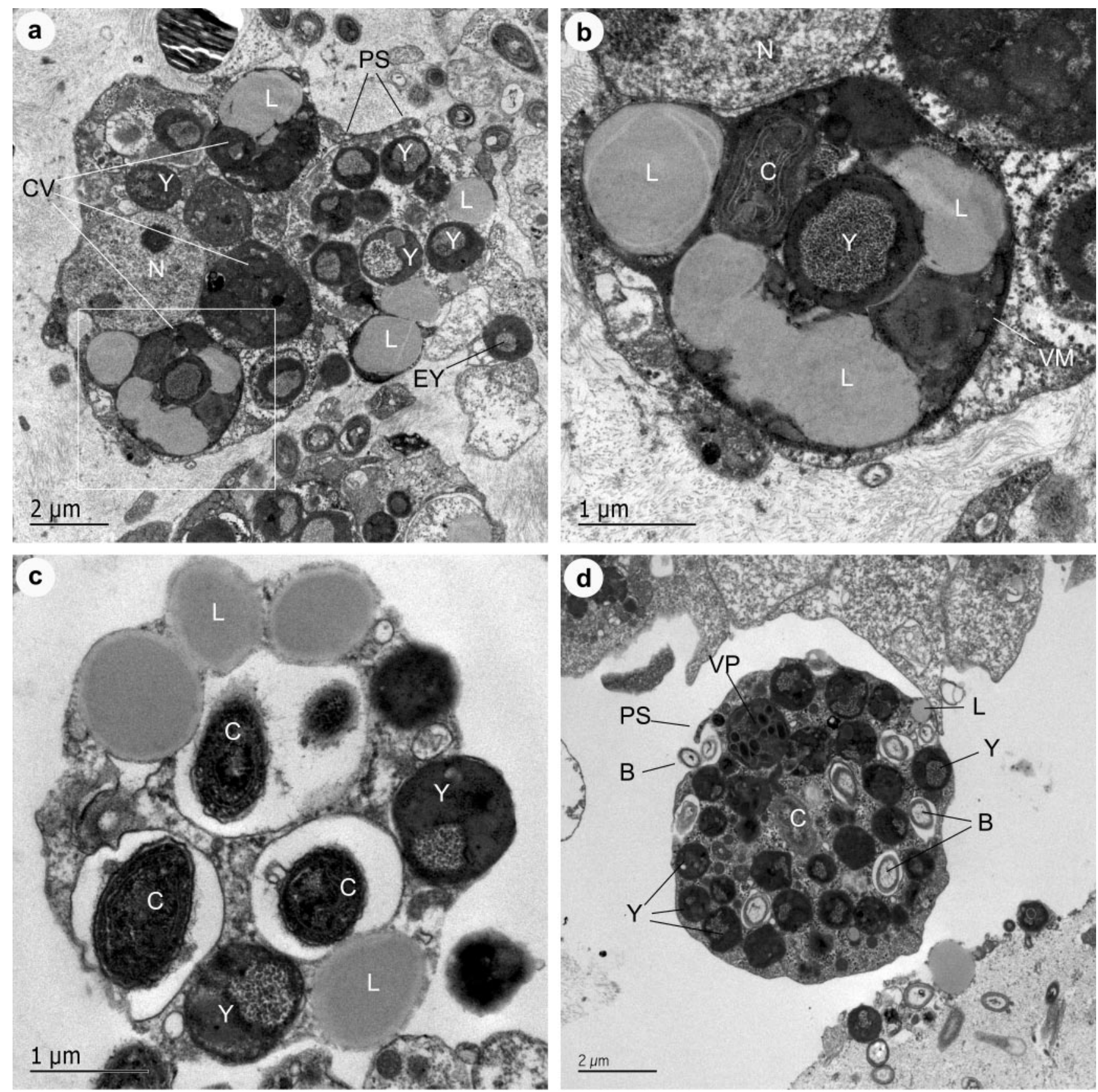

Figure 8. Detail of nurse cells. (a) Large nurse cell showing a nucleolated nucleus (N) and charged with lipid granules (L) and abundant yeasts (Y), either isolated in the cytoplasm or in groups within complex vacuoles (CV). Note that a pseudopodium (PS) from the large nucleate nurse cell is being emitted towards the smaller, anucleate nurse cell by the side, which will apparently be engulfed. Note also the occurrence of an intercellular yeast cell (EY). (b) Detail of Fig. 8a showing one of the complex, membrane-bounded vacuoles in the large nucleate $(\mathrm{N})$ nurse cell, which contains a yeast $(\mathrm{Y})$, a cyanobacterium $(\mathrm{C})$, and several lipid granules (L). (d) Detail of a small anucleate nurse cell in the sponge mesohyl, containing several cyanobacteria (C), yeasts (Y), and lipids (L). Note that this cell is similar in size and content to the inclusion within the large nucleate nurse cell described in Fig. 8a, b. (d) Large anucleate nurse cell in an excurrent canal immediately before egg release by the sponge. It contains vitelline platelets (VP), lipids (L), yeasts $(\mathrm{Y})$, cyanobacteria $(\mathrm{C})$, and heterotrophic bacteria (B). Note a small pseudopodium (PS) engulfing two intercellular bacteria. 

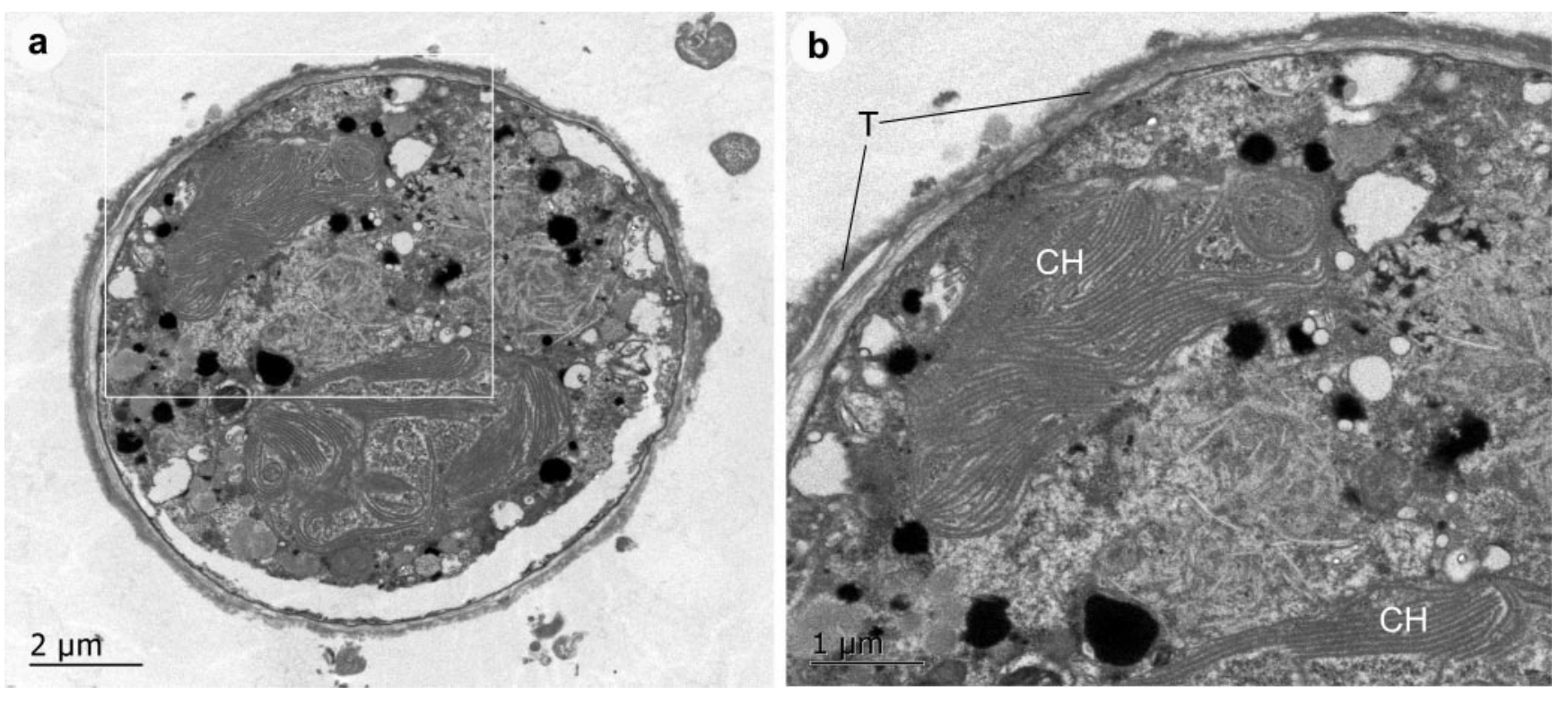

Figure 9. (a) Intercellular individual of the dinoflagellate Symbiodinium microadriaticum. (b) Enlarged area of Fig. 9a showing a detail of the theca (T) and chloroplasts $(\mathrm{CH})$.

is corroborated not only by the subcellular structure of these chitin-walled cells, but also by their characteristic cell division by fission. Some internal membranes of the yeast, particularly the nuclear membrane, and some membranous organelles, such as the small mitochondria, were hard to visualize in intact yeasts contained in either the oocytes or adult tissue. The failure of TEM to resolve these structures is probably caused by using a fixation protocol more appropriate for animal cells than yeast cells. Because we never expected yeasts to occur in these sponge eggs, we chose our fixative as the best option for studying the sponge gametes. However, the thick wall of yeasts acted as a barrier against diffusion of the fixatives, causing a deficient fixation of the nuclear membrane and the mitochondria; other organelles, such as the abundant ribosomes, the peroxisome, and the vacuole, were efficiently fixed. Nuclear and mitochondrial membranes were better preserved in yeasts whose wall had been entirely or partially degraded by direct exposure to either the seawater of the aquiferous canals or the mucous matrix of the egg strands. These results are consistent with reports that successful visualization of the nuclear membrane and mitochondria in yeasts requires enzymatic digestion of the cell wall (Bauer et al., 2001).

Unlike the cell walls in hyphal fungi, those of most studied yeasts contain very small quantities of chitin $(0 \%-$ $4 \%$ ), which mainly concentrates in wall scars (Walker, 1998). To identify chitin in the cell wall, we used a chitinlabeling complex at various experimental concentrations, a strategy followed to deal with unexpectedly low or high chitin content in the cell wall of our putative yeasts. Intermediate concentrations ( $1 / 10$ for egg samples and $1 / 5$ for tissue samples) gave highly specific labeling on yeast walls and resulted in enough gold particles per yeast to reveal consistent distribution patterns of chitin (e.g., Figs. 2b; 3a, b). The lowest concentration (1/50) yielded highly specific labeling of walls but often resulted in too few gold particles per yeast. In contrast, the highest concentration assayed $(1 / 2)$ produced specific labeling of cell walls and fission scars with many gold particles, but also showed persistence of a few gold particles at nonspecific sites in the intercellular mesohyl and egg cytoplasm after rinsing (e.g., Figs. $5 \mathrm{~d}$; 6d). Because the binding of gold particles to wall sites was highly specific at low and intermediate concentrations of the labeling solution, the occasional nonspecific labeling obtained at very high concentration (1/2) cannot be interpreted as a failing in the specificity of the reaction, but as a shortcoming in washing out some of the unattached gold particles after incubation.

Previous investigations of microsymbionts in Mediterranean Chondrilla nucula (Gaino, 1980) and in Pacific $C$. australiensis (Usher et al., 2001, 2004b) reported abundant symbiotic bacteria and cyanobacteria in both adult tissues and eggs, but no presence of fungi. However, these reports documented subspherical yolk inclusions that are virtually identical in size and substructure to the endosymbiotic yeast described herein. These findings leave little doubt that the symbiosis between yeast and Chondrilla is not limited to the Caribbean area, but also occurs in the Mediterranean and the Australian Pacific and involves at least three sponge species. Interestingly, although $C$. nucula has traditionally been described as a cosmopolitan species, several independent studies have suggested that at least the Caribbean and Mediterranean populations are unlikely to be conspecific (Klautau et al., 1999; Usher et al., 2004c). In the Caribbean, this 
thickly encrusting sponge is common in reefs, where in some areas it can occupy a large percentage of the available hard substrata and even overgrow living corals (Maldonado et al., 2005). Part of this competitive success derives from its ability to grow in well-lit sites that are exposed to predation. This ability is fostered by the production of predator-deterring metabolites that have been suggested to be of microsymbiotic origin (Swearingen and Pawlik, 1998). Indeed, the remarkable abundance of microsymbionts in all Chondrilla species suggests that these organisms must play a relevant role in the sponge metabolism. The development of a mechanism by which the sponge nurse cells collect and choose the endosymbiotic bacteria, cyanobacteria, and yeasts to be vertically transmitted to the next sponge generation is evidence of the mutualistic character of this relationship. As it is known from several sponges and other invertebrates with abundant microsymbionts, the principal benefit to the host is that the symbionts may provide nutrients, protection against ultraviolet light, and even predator-deterring chemicals. The abundance of yeasts in close association with lipids within both nurse cells and oocytes is reminiscent of the occurrence of wall-less yeast propagules (i.e., mycosomes) in senescent plastids of plants, algae, and cyanobacteria, where they are postulated to assimilate lipids of the host (Atsatt, 2003).

It is worth noting that, while bacteria and cyanobacteria are often enclosed in vacuoles of both nurse cells and oocytes, yeasts are consistently in direct contact with the cell's cytoplasm. "Inclusions" similar to the yeasts occurring in Chondrilla have not been found in eggs, larvae, or adult tissue of any other sponges we have investigated over many years, nor have they been reported in the abundant literature on sponge histology. Therefore, it appears that these yeasts are exclusively associated with sponges in the genus Chondrilla. Because yeasts typically exhibit high specialization for habitat, the occurrence of similar vertically transmitted yeasts in Chondrilla species from distant locations such as the Mediterranean, the Caribbean, and the Australian Pacific (Gaino, 1980; Usher et al., 2001, 2004b) suggests that this endosymbiosis evolved before or during diversification of the genus Chondrilla. Alternatively, by assuming that this yeast was once free-living and widespread in different marine environments, one could argue that the symbiosis might be relatively recent and that yeasts entered species of Chondrilla independently in different oceans because these sponges provide a unique, suitable physiological environment. Nevertheless, the fact that yeasts appear to degenerate rapidly when released from the sponge's physiological environment by either accidental oocyte breakage or nurse cell apoptosis suggests that they are unlikely to survive outside the sponges. Further investigations are needed to clarify whether this yeast is an obligate symbiont lacking stages external to the sponges or can occur as a free-living organism at some stage.
Growth of hyphal fungi in laboratory assays may be due not only to laboratory contamination of sponge tissue samples and culture plates, but also to germination of dormant spores dispersed to sublittoral waters and accidentally carried by the assayed sponges. We have no direct evidence of the latter process, but the occasional presence of pollen grains belonging to the pine tree Pinus pinaster has been observed on some Mediterranean sponges and in water samples taken at the base of the littoral cliff (Maldonado, pers. obs.), suggesting that such contamination cannot be ruled out. Our results strongly suggest the need to reexamine previous reports on the occurrence of hyphal endosymbiotic fungi in marine sponges. That fungi proliferate in the laboratory after placement of sponge tissues in growth media needs to be reconfirmed by visualization of the alleged fungal symbionts inside sponge cells. The immunocytochemical technique presented herein provides a useful and simple method to approach this issue.

\section{Acknowledgments}

The authors thank Dr. Craig M. Young for logistical support during sampling at the Caribbean Marine Research Center (CMRC) at Lee Stocking Island. Dr. Dan McCarthy and CMRC staff assisted in field work, and Almudena García aided in sample preparation for the histological study. Dr. Peter Atsatt and Dr. Rosa Aligé are gratefully acknowledged for comments on early drafts of this manuscript and for providing extensive information on immunocytochemical and genetic methods for the detection of fungi. This study was supported by grants from The Perry Institute for Marine Science (CMRC-00-26) and the Spanish Ministry for Science and Technology (MCYTBMC2002-01228).

\section{Literature Cited}

Atsatt, P. R. 2003. Fungus propagules in plastids: the mycosome hypothesis. Int. Microbiol. 6: 17-26.

Bauer, C., V. Herzog, and M. F. Bauer. 2001. Improved technique for electron microscope visualization of yeast membrane structure. $\mathrm{Mi}$ crosc. Microanal. 7: 530-534.

Benhamou, N., and P. J. Lafontaine. 1995. Ultrastructural and cytochemical characterization of elicitor-induced structural responses in tomato root tissues infected by Fusarium oxysporum f.sp. radicislycopersici. Planta 197: 89-102.

Bringmann, G., G. Lang, J. Mühlbacher, K. Schaumann, S. Steffens, P. G. Rytik, U. Hentschel, J. Morschhäuser, and W. E. G. Müller. 2003. Sorbicillactone A: a structurally unprecedented bioactive noveltype alkaloid from a sponge-derived fungus. Pp. 231-253 in Sponges (Porifera), W. E. G. Müller, ed. Springer, Berlin.

Frens, G. 1973. Controlled nucleation for the regulation of the particle size in monodispersed gold solutions. Nat. Physic. Sci. 241: 20-22.

Gaino, E. 1980. Indagine ultrastrutturale sugli ovociti maturi di Chondrilla nucula Schmidt (Porifera, Demospongiae). Cah. Biol. Mar. 21: 11-22.

Horisberger, M., and J. Rosset. 1977. Colloidal gold, a useful marker 
for transmission and scanning electron microscopy. J. Histochem. Cytochem. 1977: 295-305.

Imhoff, J. F., and R. Stöhr. 2003. Sponge-associated bacteria: general overview and special aspects of bacteria associated with Halichondria panicea. Pp. 35-57 in Sponges (Porifera), W. E. G. Müller, ed. Springer, Berlin.

Klautau, M., C. A. M. Russo, C. Lazoski, N. Boury-Esnault, J. P. Thorpe, and A. M. Solé-Cava. 1999. Does cosmopolitanism result from overconservative systematics? A case study using the marine sponge Chondrilla nucula. Evolution 53: 1414-1422.

Maldonado, M., and C. M. Young. 1998. Limits on the bathymetric distribution of keratose sponges: a field test in deep water. Mar. Ecol. Prog. Ser. 174: 123-139.

Maldonado, M., M. Durfort, D. McCarthy, and C. M. Young. 2003. The cellular basis of photobehavior in the tufted parenchymella larva of demosponges. Mar. Biol. 143: 427-441.

Maldonado, M., $M^{\mathrm{a}}$. C. Carmona, Z. Velásquez, A. Puig, A. Cruzado, A. López, and C. M. Young. 2005. Siliceous sponges as a silicon sink: an overlooked aspect of benthopelagic coupling in the marine silicon cycle. Limnol. Oceanogr. 50(3): 799-809.

Peter, W., and I. Latka. 1986. Electron microscopic localization of chitin using colloidal gold labeled with germ agglutinin. Histochemistry 84: 155-160.

Proksch, P., R. Ebel, R. A. Edrada, V. Wray, and K. Steube. 2003. Bioactive natural products from marine invertebrates and associated fungi. Pp. 117-142 in Sponges (Porifera), W. E. G. Müller, ed. Springer, Berlin.

Reynolds, E. S. 1963. The use of lead citrate at high $\mathrm{pH}$ as an electron opaque stain in electron microscopy. J. Cell Biol. 17: 208-212.

Rosell, D. 1993. Effect of reproduction in Cliona viridis (Hadromerida) on zooxanthellae. Scient. Mar. 57: 405-413.

Rützler, K. 1990. Associations between Caribbean sponges and photosynthetic organisms. Pp. 455-466 in New Perspectives in Sponge Biology, K. Rützler, ed. Smithsonian Institution Press, Washington, DC.

Simpson, T. L. 1984. The Cell Biology of Sponges. Springer-Verlag, New York.

Swearingen, D. C., and J. R. Pawlik. 1998. Variability in the chemical defense of the sponge Chondrilla nucula against predatory reef fishes. Mar. Biol. 131: 619-627.
Trillas, M. I., L. Cotxarrera, E. Casanova, and N. Cortadellas. 2000. Ultrastructural changes and localization of chitin and callose in compatible and incompatible interactions between carnation callus and Fusarium oxysporum. Physiol. Mol. Plant. Pathol. 56: 107-116.

Unson, M. D., N. D. Holland, and D. J. Faulkner. 1994. A brominated secondary metabolite synthesized by the cyanobacterial symbiont of marine sponge and accumulation of the crystalline metabolite in the sponge tissue. Mar. Biol. 119: 1-11.

Usher, K. M., J. Kuo, J. Fromont, and D. C. Sutton. 2001. Vertical transmission of cyanobacterial symbionts in the marine sponge Chondrilla australiensis (Demospongiae). Hydrobiologia 461: 15-23.

Usher, K. M., S. Toze, J. Fromont, J. Kuo, and D. C. Sutton. 2004a. A new species of cyanobacterial symbiont from the marine sponge Chondrilla nucula. Symbiosis 36: 183-192.

Usher, K. M., D. C. Sutton, S. Toze, J. Kuo, and J. Fromont. 2004b. Sexual reproduction in Chondrilla australiensis (Porifera: Demospongiae). Mar. Freshw. Res. 55: 123-134.

Usher, K. M., D. C. Sutton, S. Toze, J. Kuo, and J. Fromont. 2004c. Biogeography and phylogeny of Chondrilla species (Demospongiae) in Australia. Mar. Ecol. Prog. Ser. 270: 117-127.

Vacelet, J. 1970. Description de cellules a bactéries intranucléaires chez des éponges Verongia. J. Microsc. 9: 333-346.

Vacelet, J. 1975. Ėtude en microscopie électronique de l'association entre bactéries et spongiaires du genre Verongia (Dictyoceratida). $J$ Microsc. Biol. Cell. 23: 271-288.

Vacelet, J., and C. Donadey. 1977. Electron microscope study of the association between some sponges and bacteria. J. Exp. Mar. Biol. Ecol. 30: 301-314.

Walker, G. M. 1998. Yeast Physiology and Biotechnology. J. Wiley, Chichester, England.

Wilkinson, C. R. 1978a. Microbial associations in sponges. I. Ecology, physiology, and microbial populations of coral reef sponges. Mar. Biol. 49: $161-167$.

Wilkinson, C. R. 1978b. Microbial associations in sponges. II. Numerical analysis of sponge and water bacterial populations. Mar. Biol. 49: 169-176.

Wilkinson, C. R. 1978c. Microbial associations in sponges. III. Ultrastructure of the in situ associations in coral reef sponges. Mar. Biol. 49: 177-185. 